\title{
The Investigation and Comparison of Experience of Divorce in Divorced Men and Women (Meanings, Contexts, Outcomes, and Adjustment after Divorce)
}

\author{
Aida Abolhassni ${ }^{1}$, Taghi Pourebrahim ${ }^{2}$, Abolghasem Khoshkonesh ${ }^{2}$ \\ ${ }^{1}$ Master Degree, Shahid Beheshti University, Tehran 1983969411, Iran \\ ${ }^{2} \mathrm{PhD}$ Professor, Shahid Beheshti University, Tehran 1983969411, Iran \\ Correspondence: Aida Abolhassni, Master Degree, Shahid Beheshti University, Tehran 1983969411, Iran.
}

Received: October 12, 2017

doi:10.11114/ijsss.v5i12.2774
Accepted: October 25, $2017 \quad$ Available online: November 8, 2017

URL: https://doi.org/10.11114/ijsss.v5i12.2774

\begin{abstract}
The aim of this qualitative study is to investigate the experience of divorced in men and women with respect to implications, backgrounds, consequences and compatibility of divorce and compares their experiences in this regard. To this end, the phenomenology method of qualitative research has been adopted in this study. 25 persons (13 females and 12 males) were selected using purposive sampling based on standard sampling strategy until data saturation was achieved. Semi-structured interviews were used to collect data. To analyze the data derived from phenomenological interviews, thematic analysis was employed. The research findings were divided into four general categories of divorce implications, backgrounds for divorce, divorce consequences and divorce adaptation. Each of these categories was further divided into sub-themes. In the category of divorce implications, two themes of perceived implications of divorce and semantic dimensions of divorce were discussed. The sub theme related to the perceived implications of divorce was additionally divided into three sub scales of divorce salvation, divorce as the last resort and negative implication of divorce. The sub-theme of semantic dimensions of divorce was also divided into three sub scales related to social, personal and sexual dimensions of divorce. In this study, the emphasis has been on the backgrounds for divorce rather than causes of divorce. The findings related to the backgrounds for divorce include 9 sub-themes which were divided into four general themes associated with large, medium, small and interactive dimensions. The consequences of divorce consisted of 17 sub-themes which were divided into three general subjects associated with economic, sociocultural and personal dimensions. Compatibility was also composed of 9 sub-themes divided into three general themes related to personal, domestic, socioeconomic and the presence of children. As for the disparity between men and women experience, the results showed that divorce experience was affected by the gender of participants in cultural and social settings. As for the implications and grounds for divorce, men and women had identical experiences, but there they were different in term of how they had gained those experiences. This difference was especially significant with respect to divorce consequences and compatibility. For men, divorce consequences are more notable with respect to emotional and personal dimension but for women, the social and cultural dimension is highlighted. Moreover, divorce tends to be considered as an internal matter for men and an external matter for women. Finally, it is concluded that this structure demonstrates the interactive nature of divorce dimensions, divorce, the reciprocity of divorce backgrounds, and structural relationship between various aspects of divorce. Thus, any preventive programs, counseling and intervention in divorce crisis should take such structural, complex and multidimensional relationships into consideration.
\end{abstract}

Keywords: divorce, divorced, implications of divorce, backgrounds of divorce, consequences of divorce, compatibility of divorce, phenomenology method

\section{Introduction}

Mental health of future generations depends on family mental health as a station full of love and peace for development and growth of talents, that any harm to it, will have negative effects for the next generations. And many social organizations will be involved. The nature of emotional atmosphere of family includes parents' relation with children, children to each other and parents with each other. Marital relationship has been described as the most important and most fundamental relationship of humans, because it provides the basic structure for relationship between family members and education of the next generation. One of the greatest challenges of married life is a phenomenon called divorce. 
The most reliable indicator of marital distress is divorce. This confusion unstable marriage system so that the couples are discouraged from each other and are not able to forgive the actions, thoughts and negative emotions of each other and their belief is that they do not see no choice except divorce. So with this interpretation it can be said, divorce is the most common manifestation of conflict. Wiseman (1975) believes divorce is a process that starts with an emotional crisis of both couples and ends when they try to resolve marital conflicts, through separation, by entering into a new situation with different roles in life. Wiseman believes passing from divorce process, he refers to as a process full of sorrow as well as growth includes five intertwined stages: denial, loss and depression, anger and bias, change of lifestyle and identity, acceptance and solidarity. McKnight (2009) believes divorce involves three phases: 1 - period before divorce (decision making) 2.During the course of divorce (reconstruction period) and (3) period after divorce (recovery phase). Each of the phases is consisted of the steps that each step involves sub steps. The first period begins with experiencing the growing dissatisfaction in each of the couple's marital relationship and continues with legal process of divorce and discussing about it with friends and family. The second period is the time to focus on the facts related to economic issues of divorce, deciding about the location of each spouse after divorce, custody and guardianship of children and so on. That this period includes mixed emotions such as fear, loneliness, anger and rejection. In the third period, people try to discover new experiences and identity and factors of new love. This perio $d$ is exciting for some and associated with regret and resistance in accepting reality for others.

Divorce is a painful experience for many people. Although some needs has caused God to legitimize divorce, but religious policies has been established to invite people to preserve family and avoid divorce. Traditional teachings know divorce as an abominable lawful thing in the sight of God. And a house in which divorce is located resembles the wreckage and a man divorces his wife unreasonable is called damned.

In the past few decades, divorce in our society that is an Islamic society and protects moral values, have had a growing pace and has attracted the attention of experts. This concern is about the rapid growth of divorce, divorce practices and lack of mechanisms that reduce or minimize the aftermaths of risky consequences lead to divorce; but what most bothers the mind is that these concerns and precise and coordinated policies and programs have not been analysed comprehensively to open a way to reduce the problems and only concerns have been expressed, as far as divorce with addiction, poverty and unemployment are now considered among the most important social problems.

KALANTARI et al. in a research called reviewing over three decades of research about the causes of divorce in Iran, have divided the causes of divorce into four categories: social, psychological, familial and economic factors. At social level, age at marriage and the age difference between spouses is the most common factor. Global research has also emphasized on these factors. And in most social studies an important factor related to the incidence of divorce has been marriage age. In researches conducted about the impact of domestic violence and family issues, the effect of betrayal and addiction in divorce has been demonstrated. Lack of skills in psychological behaviour and personality and mental disorders are factors affecting divorce that have been mentioned in about 7 percent of internal investigations. At the economic level of causes of divorce, financial problems in about $10 \%$ of internal investigations have been mentioned. Studies have pointed out to many reasons such as lack of mutual understanding, disobedience, unemployment, financial problems, addiction, interventions of other persons, differences in the level of education and age differences, communication problems, narcotic material addiction, family involvement and one the partner's mental illness , inadequate knowledge of couples about each other, disagreement, family and other persons involvement in the life of couples, unemployment, forced marriage, shortage of life skills, addiction, low age at marriage, urbanization, physical or mental illnesses of couples, lack of sexual and relational skills in marriage, others' meddling in the lives of couples, difference in status between the couples, married life satisfaction and positive impression about the consequences of divorce, lack of accountability- involvement of families, inability to establish emotional relationships, indifference to his wife, unfaithful wife, having problem to have desired sexual activity, do not meet each other expectations, low age and addiction, initial adverse selection and excessive dependence of one spouse to the family, lack of communication skills, adultery by husbands and sexual exclusion of women.

Researches by many inside and outside the country are looking to answer the question why some marriages lead to divorce? One way to answer this question is using qualitative research and interviews to understand the experiences of persons about divorce. Because the main thing is that divorce experience varies in different cultures and different ethnicities. And the results of studies also prove these differences. For example, Moore and Schwebel (1993) found that reasons for divorce reported by white are related to parenting problems and communication, while African-Americans have mentioned to trans-marital relationships and physical abuse as the reason for their divorce. Also according to the results by Chang (2003), the reasons reported by immigrant Korean men and women were different with Americans. Korean women have mentioned to tangible problems such as abusive behaviours and financial problems as the reason for divorce, while American women have mentioned more to the abstract and emotional reasons. So marriage and divorce does not occur in a vacuum, but occurs in a cultural and social context. Besides, divorce may vary among 
different cultures. It also differs among subcultures. So it is possible that the reasons for divorce in various provinces of the country to be somewhat different.

This study unlike quantitative procedures attempts applying qualitative approaches by phenomenology to search divorce experience and studies platforms and experiences of divorced people. Because based on descriptions, use of this method to detect structures of marital phenomenon in psychology and family counseling is a necessity and filling this lack is considered another necessity. This approach does not have a cross-over view toward phenomenon and totally is dependent on the cultural context and perspective. Thus, to study the process of divorce in Iranian culture and experiences of men and women to understand difference between them, this research was conducted.

This study attempts to study divorce experience based on its' causes and consequences for men and women who have participated in this study. Divorce is amongst those concepts which should be studied in a context that occurs in it , till with the identification of factors involved, the most appropriate preventive measures to be applied by relevant authorities to reduce it as possible. Meanwhile understanding the language of divorce and its description by men and women who have gone through the same experience can increase our knowledge about the different interactions between the sexes.

\section{Methodology}

\subsection{Objective}

This study research about the investigation and comparison of experience of divorce in divorced men and women in their meanings, contexts, outcomes and adjustment after divorce is happen.

\subsection{Participants}

This study population includes divorced men and women in Tehran that at least have had one month experience of common life with their couples and at least three months and maximum ten years had been passed from the moment they had been legally divorced and only once they were married. In this study, 25 participants (13 women and 12 men) have been selected by purposive sampling method, so that data have been saturated. Their average ages was between 15 and 49 years and were not suffering from mental illness.

\subsection{Instrument}

The way to collect data was through semi-structured interviews with the participants to search for meanings, contexts and consequences of divorce. After recording each interview, data obtained from the interview has been transcript. After transcription of the interview, the first versions were obtained for analysis. After rereading of versions and its compatibility with the recorded files, in order to check the accuracy of the contents of versions, a copy of relevant version was sent for each participant and then if there was any error or omission they were corrected. Because in qualitative research the process of collecting and analyzing of data is synchronize, after finishing of the first interview and transcribe of it , then second interview is done and then the third interview and ... . This process of simultaneity of data collection and analysis was conducted until data saturation.

In addition, because one of the primary methods used to provide valid results from phenomenology, includes the process of "epoché", in order to raise awareness about the theories and research and preventing potential abuse of the phenomenon under study, researcher constantly uses an active process called "bracketing". And after each interview, by reviewing of interviews and experiences in mind during the interview, records each feeling and reaction in a notebook. The existence of this notebook helped researcher in case of outbreak of thoughts and feelings that are derived from potential biases, indicates them and having ability to control them in future dialogues and considers the effects of these thoughts and feelings in order to direct interviews during analysis.

In order to analyzing research data, thematic analysis procedure (content) was used. Thematic analysis is a method for identifying, analyzing and reporting available patterns in qualitative data. Pattern is a model derived from data obtained through conceptual order. This method is a process for analyzing textual data and diverse data is changed into a rich and detailed data. Encoding initial process to create a theme was done in a row of data. Most qualitative researchers believe that thematic analysis method is very useful to learn the meaning in a set of data.

\section{Steps in thematic analysis}

First step: Becoming familiar with the data

Second step: Generating initial codes

Third step: Searching for themes

Fourth step: Reviewing themes

Fifth step: Defining and naming themes 
Sixth step: Producing the report

About the acquisition and exploration of the main issue that is an axis for forming of paradigmatic model and organizing of other elements associated with it, it should be said that researcher have done interviews and asked about their experiences and views in this field to achieve the real characteristics of the phenomenon for divorced men and women. In the process of data collection slowly concepts and propositions in this regard have been accumulated, until from the tenth interview the conclusion of interviews and checking of statements guided us toward the main field that is the experience of divorced men and women. Then we tried to set up the next questions around it that in thirteenth interview, theoretical saturation of data was obvious. In other words, to ensure about this concept and filling conceptual holes of the model, interviews continued until the thirteenth interview.

\subsection{Procedure}

In this study applied procedure has been qualitative. Qualitative procedure discovers phenomenon as they have occurred and in their natural situation and studies them based on meanings that people consider for them.

\section{Results}

Subjects in 5 main components within 10 dimensions of paradigmatic model were placed: semantic dimension of divorce (1 subject) base of divorce ( 1 subject), divorce consequences ( 3 subjects); probable risks ( 1 subject), outcomes ( 3 subjects) and compatibility after divorce (3 subjects). Its details are shown in Figure 1, encoding data.

\section{Open Coding Stage: 43 Proposition Initial Concept}

\section{Stage Axial Coding: 5 the Main Issue and 10 Sub- Categories}

A. Dimension Of Meaning: 1.Divorce Perception( Divorce mean liberating factor, Divorce mean last resort, Divorce mean negative charge); 2. Divorce Dimensions (a personal structure, a gender structures and a cultural and social structures).

B. Divorce Context: Divorce due to 1. Drug addiction, Marital skills, Financial and economic issues, Married very young age, Romantic love and marriage, Feel remorse and guilt, Failure to fulfill the duties of wife, Betrayal and infidelity, Low vibration in religious and laxity in life, Social and cultural changes,

Emotional and psychological problems.

C. Divorce Outcomes: 1.Social outcomes( Control, Social stigma, Cold relation between close family, Located about greed, Difficulty in marrying again, Fear of marriage, Lack of re-marriage question, In place of charge and abusive behavior); 2. Economic outcomes( Financial problems); 3. Personal outcomes( Feeling lonely, Feel down, Feel victim, Guilt, Hatred and Regrets). D. Risks: 1.Depression for women and Stress and Anxiety for men.

E. Divorce Adjustment: 1. Personal and individual factors (Growth and personal excellence, Power liberation from the past, The ability to adapt to reality, Power restored); 2. Family factors, Economic and

Social( Family support and lack of financial support); 3. The presence of children( Improve family life due to the presence of children and inability to give up marriage).

CC. The Main Phenomenon: Divorced men and women exnerience the nhenomenon of divorce.

\section{The Selective Coding: 6 Model's Dimension}

Divorce Meaning( 1 category); Divorce Context( 1 category); Divorce Outcomes( 3 categories); Risks( 1 category); Outcomes( 3 categories) and Adjustment after divorce( 3 categories).

Figure 1. Process of data management and development of model in three encoding phases 
Table 1: The Results of open and axial coding with a subcategories about Meaning of Divorce and differentiated by Gender

\begin{tabular}{|c|c|c|c|c|}
\hline Frequency & Categories & Subcategories & Categories & General Category \\
\hline Disaggregated & by Gender & & & \\
\hline Women & Men & & & \\
\hline 13 persons & 12 persons & & & \\
\hline 3 & 8 & Liberating Factor & Semantic Perception & Divorce Meaning \\
\hline 10 & 2 & Last Resort & of Divorce & \\
\hline 13 & 11 & Negative Charge & & \\
\hline 10 & 4 & A Personal Structure & $\begin{array}{c}\text { Semantic Aspects of } \\
\text { Divorce }\end{array}$ & Divorce Meaning \\
\hline 13 & 12 & A Gender Structures & & \\
\hline
\end{tabular}

9

Men and women participating in this study have had the same meanings for divorce. But how they have experienced this meaning have changed according to gender. This means that the gender of participants in this study who have experienced a divorce have made some differences. This means that in each gender a meaning has been dominant. So gender is effective in understanding the meaning of divorce.

Women participating in this study often have understood divorce as the last resort and they have understood the quantitative meaning for liberating sense of divorce. On the other hand, men often have understood divorce as liberating factor and few men imagine it as the last resort. This vision about di vorce in this way by participants in this study has been because of the consequences of experienced divorce, therefore women participating in this study because of experiencing economic, social and cultural consequences of divorce have chosen it as a last resort. Most of these women were involved in their husbands' addiction and finally when they have seen there is no hope to change the situation have selected divorce as the last resort. In the same way women in minority group who have sensed divorce as a liberating factor, their reason for divorce has been most because of emotional and communication factors and have experienced less economic and cultural consequences because of family support. In men participating in the study, those who have chosen divorce as the last resort have had children and they haven't applicant for divorce.

Men and women in this study in the first semantic associations have considered divorce has a negative charge and have experienced this negative charge in social and cultural contexts. But also women participating in this study due to the social and cultural consequences of divorce for women considered it as a negative thing. Overall divorce for both sexes has had a negative concept. But if the participant has not been the applicant for divorce and has had children, and socially and culturally has experienced severe consequences, has considered more negative.

Women and men in this study each have looked from their own perspective to divorce, that these views have been influenced by their gender and their social and cultural context. Divorced men and women in this study each have blamed the other sex in their divorce and have considered their personal fault continue a relation that there is no hope to improve the situation in married life, while they thought they should at early stages thought about divorce. So in men and women perceptions of their personal meaning of divorce have led to the divorce and their divorce was inevitable. In divorced persons in this study gender is a main factor and each cast blame upon the other sex. And meaning of divorce for them is based on gender and divorce has made them pessimistic about their opposite sex.

Participants in this study will look the experience of divorce based on gender and their gender has been effective in order to comprehend the meaning of divorce. But they have been incapable of understanding the opposite sex and they have not understood gender differences of each other after divorce have blamed the opposite sex. In their interviews they have referred to opposite sex as men and women together that shows their misunderstanding about gender. Of course, gender can be built in socio-cultural space. This means that in social and cultural contexts gender differences are more pronounced. Women more than men have considered to social and cultural implications and they thought men in this area have more comfortable experience, because women after divorce have more social, cultural and economic concerns than men; so social and cultural dimension is significant in shaping gender dimension. By comparing the experience of men and women in this study we found that divorce has a multi-dimensional meaning that it cannot be separated from social and cultural context as well as gender. 
Table 2. The Results of open and axial coding with a subcategories about Divorce Context and differentiated by Gender

\begin{tabular}{|c|c|c|c|c|}
\hline $\begin{array}{l}\text { Frequency } \\
\text { Disaggregated }\end{array}$ & $\begin{array}{c}\text { Categories, } \\
\text { by Gender }\end{array}$ & \multirow[t]{2}{*}{ Subcategories } & \multirow[t]{2}{*}{ Categories } & \multirow[t]{2}{*}{ General Category } \\
\hline $\begin{array}{l}\text { women } \\
13 \text { persons }\end{array}$ & $\begin{array}{l}\text { Men } \\
12 \text { persons }\end{array}$ & & & \\
\hline 7 & 0 & Drug Addiction & & \multirow{12}{*}{ Divorce Context } \\
\hline 10 & 9 & Marital Skills & Marco & \\
\hline 2 & 3 & Financial and Economic Issues & Middle & \\
\hline 13 & 12 & Married Very Young & Wisdom & \\
\hline 10 & 8 & Romantic Love and Marriage & Inte ractive & \\
\hline 5 & 3 & Feel Remorse and Guilt & & \\
\hline 12 & 12 & Failure to Fulfill The Duties of Wife & & \\
\hline 3 & 2 & Betrayal and Infidelity & & \\
\hline 2 & 5 & Low Vibration in Religious Life and Laxity in & & \\
\hline 5 & 6 & Life & & \\
\hline 6 & 0 & Social and Cultural Changes & & \\
\hline & & Emotional and Psychological Problems & & \\
\hline
\end{tabular}

In this study, based on participants' experience for divorce 9 main platforms for men and women were recognized. These platforms were taken from the experiences of research participants. This means that men and women participating have had the same experience about the platforms caused their divorce and what makes the difference in their experience is how they experience it based on their gender.

Using narcotic material is the largest platform for divorce in women that their husbands were involved in addiction. In this study, more than half of the respondents have expressed their husband's addiction as a cause for divorce. Addiction as the most important platform in this research could create other causes of divorce. This study shows that abuse of narcotics by husbands causes their dependence to narcotic material and consumers cannot do their roles as husband as well as their job like normal people. Women who have expressed their divorce because of their husbands' addiction have complained from the violence of their husbands, financial and economic problems, frigidity and irresponsibility; So addiction directly causes other causes of divorce and in this way addiction is the leading cause of divorce because causes other causes and intolerability. A husband, who in addition to addiction, shows violence, brings financial problems and have no liability and is cold in his relationship, could not be tolerated by any partner. Addiction directly has leaded these causes of divorce for women participating in this study including: cold relationships, lack of responsibility, violence, financial and economic problems. Therefore women participating in this study who were concern about their husband addiction have experienced other painful experiences like violence and financial difficulties that they are based on addiction of husband. One of the things that disappointed women of addicted husbands and had them to insist for divorce was their husbands repeated return to use narcotics.

Based on experience of women who were divorced because of their husbands' addiction we see a two sided relationship has been experienced that these experiences pose this question whether addiction leads to divorce for these women or a marriage that have lead to divorce has led to her husbands' addiction? Most participants pointed out that addiction of husband after the marriage has taken place. Most of these women have pointed out that initially have had good times and beauty, but after a time addiction have ruined their lives. Addiction leads to frustration in women, and due to the nature of it divorce for a woman is inevitable.

Lack of marriage skills causes a sexual phenomenon and emotional divorce has been experienced by the participants. In this context the differences between men and women experiencing divorce becomes more apparent. In this study, female participants were complaining that men do not pay attention to their physical and mental needs and men are fed up with the cold and heartless. In contrast, men also refer to the lack of respect for their character and lack of understanding by women. Men and women participating in the study showed that while marriage is very beautiful, emotional and has been productive, when interviewed spoke with regret about it, with the onset of addiction problems such as infidelity, financial problems, and etc. have started and less emotion by their spouses has caused divorce. And the severity of their problems has been added and finally reached a divorce. A period started having problems and they emotionally apart and their reactions to problems and marital problems instead of solving the problem, stepped down and was blaming the other side and it is the period that the couple should seek help from specialized sources such as family counseling and strengthen and enrich it. But the lack of these skills is causing emotional divorce and finally to have legal divorce, because they have not understood the opposite sex. Men and women participated in this study in the context of marital skills have pointed to the same thing that difficult marital structure as an intermediary causes of divorce. That is the weakness of the other causes problems in marital skills, such as addiction, betrayal, and economic problems that addiction for women has been painful. And in this context, marriage women were disappointed. Men participating in a context of economic difficulties and unemployment have had a painful experience. And their life was disappointed. Based on the experiences of divorced men 
participating in this study job loss for men is a horrible thing and in terms of psychological and social feeling is a failure. As a result of job loss and financial problems he is disappointed about his role and feels his place in the family has lost.

The biggest difference between men and women participating in this study is their sexuality in a social structure and cultural context. And divorced men and women show great distance between each other. That it was grounds for divorce. In this context we faced by men and women who do not understand each other's differences and the marital platform for interacting skills is weak. Due to the lack of marriage skills, couples are apart from each other. So the first thing that is obvious in the context is gender differences. That men and women have been divorced. Each of the male and female gender by looking at her wife or husband knows that his role will not play.

The first obvious difference in this structure is the description of the men and women of irresponsibility, due to their personal experience of married life that these tags to cross to the opposite sex are stigmatized. The study showed that women experience Irresponsibility because men use narcotics and addiction has potential to ruin the individual's personal and social roles. Or young couples who lack emotional maturity and intellectual skills are dependent to family financially and emotionally, and these couples do not have the ability to play the role of a couple. From the perspective of some women in the family all needs of husband are met and a husband learns lack of responsibility. Interviews see that divorced men and women are on both sides of a continuum that irresponsible man to woman is expected to continue this role. Divorced people have difficulty in achieving a balance. These are reasonable expectations that their perception for women and men in life is expected than relationships outside of marriage.

The second obvious difference in the experience of women and men in this study is in the context of growth and advancement of women against men and women has modernizing description of divorced women and divorced men that is described regardless of marital duties. Related to the context of social change and the changing role of women, men in this study have more negative view of the demands of women. And it prevents maternal roles and women are treating a husband. On the contrary, we have to deal with women's changing roles of men against women and become more active in the community know. And again on both sides of the continuum with the couple facing each other are the two opposite poles. And like normal couples have failed to balance their roles.

In the context of marital betrayal and infidelity, men and women in the study experienced a severe negative emotional consequences are common. However, the experience of emotional differences between men and women can be seen. But both sexes have evaluated infidelity has high negative charge. And men and women in this study because of the betrayal of his wife divorced and intense experience negative emotions there. One of the common experiences of the opposite sex after experiencing betrayal is pessimistic and negative attitude to the opposite sex after divorce. The excitement experienced by men, anger, aggression and cynicism toward women. On the contrary, women are depressed and preoccupied with their treachery found. Angry men experience intense emotional state and feel their masculinity is gone. Men as well as women are not willing to give the other side. Women, but men continue to live side by side in any case we will not continue. And in any case they divorce. Emotional outcomes for participants, male and female couple standing in front of this research destroys and his role as a pale wife. Women constant attention to the issue of betrayal and consequences such as intense anger and anxiety in men pave the context of divorce. Men and women in this study had the same opinion that religious values protecting the privacy of marriage and contributes to the stability of marital relations. As a result of interviews with men and women, the study found that religious values that discourage divorce include faith in God, the sanctity of marriage, the family and religion, respect for ethical values such as commitment, trust in God, forgiveness of the wife, endured the hardships of life.

Another important change was the social and cultural context. That sex is a big difference between men and women in the structure of social changes relating to divorce has created. In this context, more women than men are involved in divorce. And the men accused of the traditional and patriarchal views on women are. Di vorced women in this study have noted that men do not want to accept the changing role of women. Men accept change for themselves. But the women are tough. Today more women are educated and have worked with men on the outside. Women work outside the home is positive. And it increases their mental health. Women are sitting at home depressed. But it should be out of the activities and roles of wife and mother, their balance. Women said, sacrificed for each one of these two roles is not allowed to benefit others and regret and depression in women. The study also proved that women who were married at a young age to study and find jobs not feel regret was not.

One of the social changes that divorced individuals referred by the expansion of communication technologies such as satellite, mobile and virtual space like the Internet. Divorced men interviewed are pessimistic about the communication technologies have found. And I pouring their lives as a result of the change of life style traditional to modern communication technology know through this. It is important that participants who had a relationship before marriage divorce pessimistic view than the change in life patterns have been through this network. While at first one of the users of these networks have been caused by changes in the patterns they experience their divorce. Study participants who were 
better educated, we believe that we cannot stop these changes. It is better that we make better use of the network. And the spouses and children training on how to use these networks have agreed.

Table 3. The Comparison of Experience of Divorce in Divorced Men and Women in Outcomes

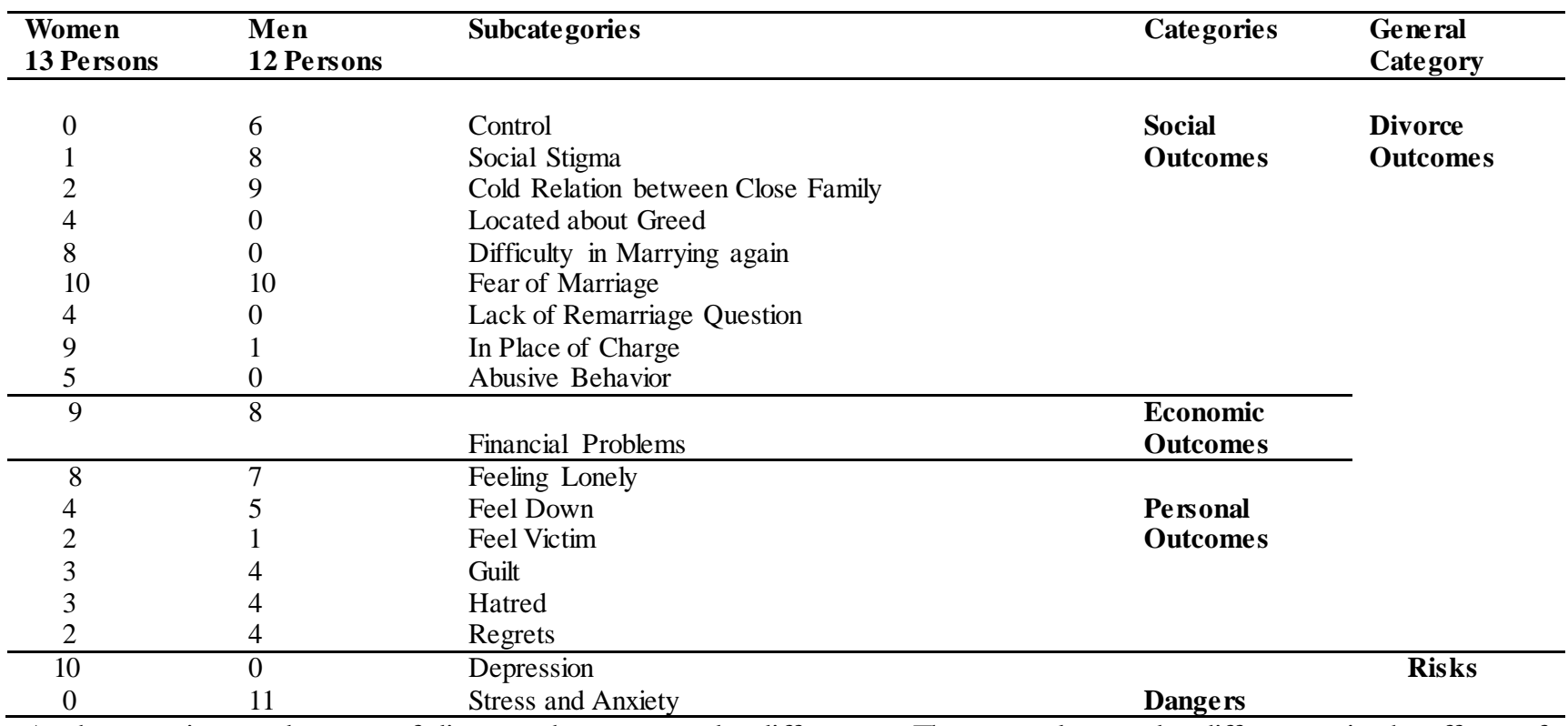

As the meanings and causes of divorce, there are gender differences. There are also gender differences in the effects of divorce. One of the features that create the difference is that their women will develop complications. But the men in this matter and because education is more men do not talk easily of their problems. For this reason, there are more specific and more obvious consequences of divorce for women than men and understanding the consequences of divorce for men is more difficult. In some ways, the severity of the consequences of divorce for men is more difficult.

Women are more likely than men to worry about the social and cultural implications. The experiences of men participating in the study to understand the emotional consequences of divorce for women, men sometimes sharply, experience. Unlike the social and cultural context of personal media such disorders as depression and psychological after divorce experience negative emotions such as pessimism and negative thinking, the men had a similar experience. Women are more pessimistic than men after divorce. This pessimism is cause of emotional problems for them and may not have the right to remarry. This pessimism makes for men in marriage, some of them are wrong again. Emotional reactions to divorce are more men than women. Men experience a lot of anger and resentment and the men who divorce their feelings of rejection are not.

Men more likely than women to engage in behavioral measures and these measures may include resorting to addictive behavior, depression, violence and other behavioral measures. One of the consequences of emotional preoccupation for men after divorce is that women living in thoughts of the past, thinking about his guilt and sin, regret and so on. As more women tell their problems. This preoccupation is more harmful to men. Men as well as women in the economic context of the economic consequences of divorce are concerned and afraid.

Table 4. The Comparison of Experience of Divorce in Divorced Men and Women in Adjustment

\begin{tabular}{|c|c|c|c|c|}
\hline \multicolumn{2}{|c|}{$\begin{array}{l}\text { Frequency } \\
\text { Dis aggregated by Gender }\end{array}$} & \multirow[t]{2}{*}{ Subcategories } & \multirow[t]{2}{*}{ Categories } & \multirow[t]{2}{*}{$\begin{array}{l}\text { General } \\
\text { Category }\end{array}$} \\
\hline $\begin{array}{l}\text { Women } \\
13 \text { Persons }\end{array}$ & $\begin{array}{l}\text { Men } \\
12 \text { Persons }\end{array}$ & & & \\
\hline 9 & 5 & Growth and Personal Excellence & Personal and & Divorce \\
\hline 5 & 2 & Power Liberation from the Past & individual & Adjustment \\
\hline 5 & 4 & The Ability to Adapt to Reality & & \\
\hline 3 & 2 & Power Restored & & \\
\hline 6 & 0 & Family Support & Family Factors, & \\
\hline 6 & 0 & Lack of Financial Support & $\begin{array}{l}\text { Economic and } \\
\text { Social }\end{array}$ & \\
\hline 7 & 5 & $\begin{array}{l}\text { Improve Family Life Due to the Presence of } \\
\text { Children }\end{array}$ & $\begin{array}{c}\text { The Presence of } \\
\text { Children }\end{array}$ & \\
\hline 10 & 9 & Inability to Give Up Marriage & & \\
\hline
\end{tabular}

Compatibility with divorce is common in men and women in this study that affected by several factors. First you have to experience the consequences of divorce. And what platforms have been led to divorce. Third the problem of children and 
fourth who divorced.

Because the consequences of divorce for women is more specific and clearer than in men, understanding the consequences of divorce for men is more difficult and so understanding its compatibility with divorce is more difficult. Unlike women, who are more in the context of social and cultural adaptation to the severe consequences of experience in this field? Compatibility of men is an internal affair. Which is connected with personal and emotional consequences after divorce are more experienced. In this study, the process of adaptation to divorce, more women than men are known. And for the detailed discovery of the field in the men need to research more and more independent.

Men sometimes experience more highly emotional consequences of divorce than women, unlike the social and cultural context of personal media such disorders as depression and psychological after divorce experience negative emotions such as pessimism and negative thinking women have had similar experiences. The study involved women adapting to social and cultural circumstances after the divorce. But because men have more experience with the consequences of a divorce are engaged in internal consistency. Divorced men have tried to catch up with individual solutions and conduct experiments. They behavioral strategies such as returning to friendly relations before marriage escape from loneliness, Cornwall drowned in work and others have selected. Social and cultural adjustment is easier for men than women, because women do not like accepting external support from family and easily after divorce can live independently. But like women, men and children after divorce affect compatibility.

\section{Discussions}

The results of current research describe a structural model. The aspects related to the divorce. Divorce is a complex and multi-dimensional generalization that has a general structure of meanings, context, and compatibility issues related to the divorce. Due to the quality of research infrastructure is the subjective meanings. That people are allowed to happen. In this study, the various meanings of divorce (divorce as a matter of liberation, divorce as a last resort and negative connotation divorce), divorce, creating a multi-dimensional structures that the most important dimension of personal, social and cultural constructions of sex after divorce. This causes a variety of different meanings for divorce. The four large platforms, middle, small and interactive are classified, so different meanings of divorce create these platforms. Personal dimension creates effective indi vidual outcomes. After the mid-effective sexual outcomes, cultural and social dimension in the creation of effective macroeconomic consequence and these aspects together in the creation of interactive media are effective (this effect is shown by the arrow). These dimensions, in turn, constitute the semantic structure divorce. As grounds for divorce under the influence meanings are formed. The consequences of divorce affected shaped platforms. Macro-economic and social-cultural contexts shape. Small bed individual consequences of divorce form. Intermediate substrates leading to the consequences of divorce are interactive and adjustable platforms in a two-way interaction and make coping with divorce. Compatibility of divorce by personal, family, economic and social can be built. This structure represents the size interactive divorce, divorce and cyclical factors, structural relationships between various aspects of divorce. In the form of semantic model on display is the study participants experienced divorce. 


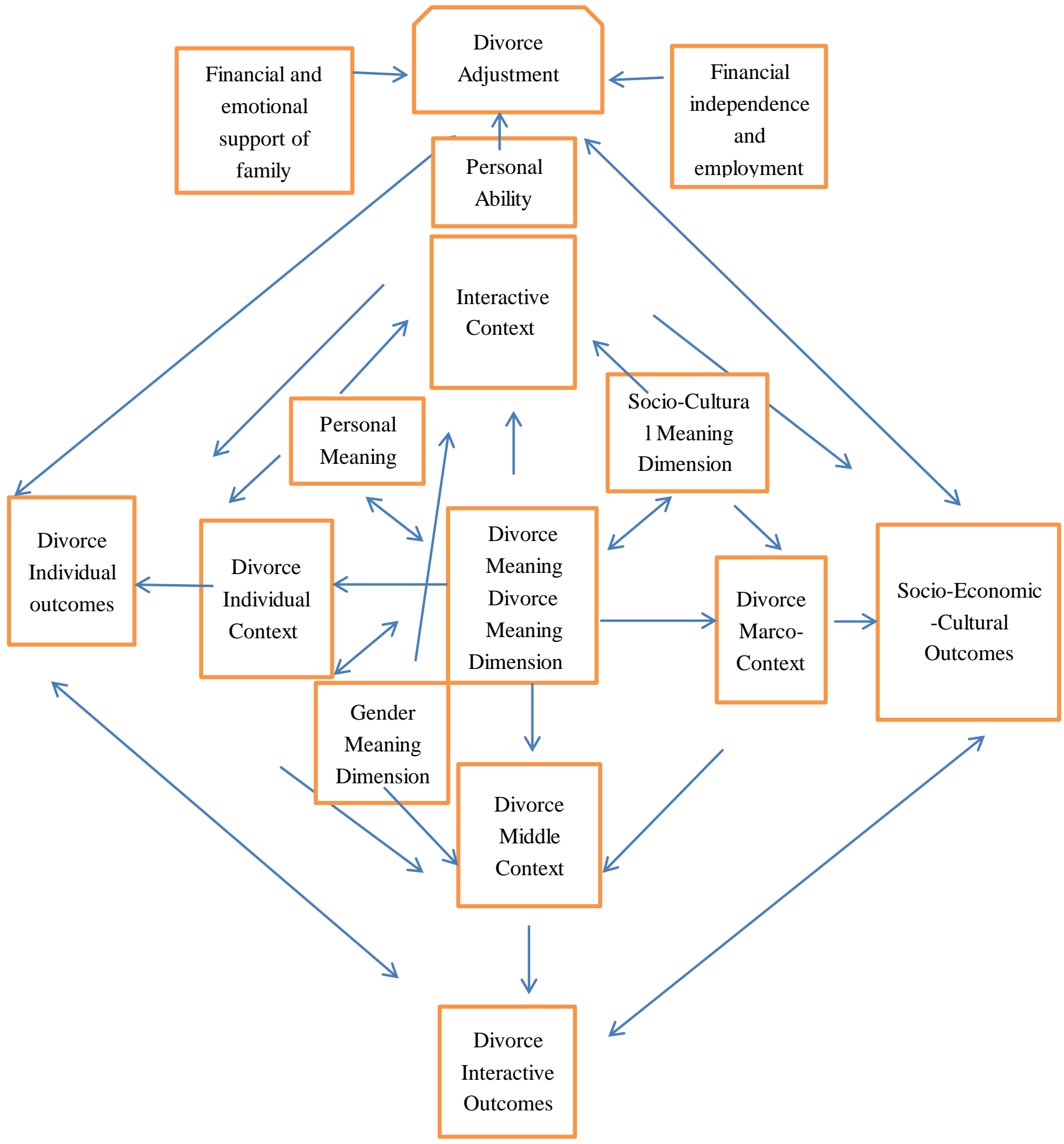

Figure 2. Semantic Divorce Model about Participants in Research Experience (Direction of arrows, represent the type of relationship)

\section{References}

Akhvan, T. M. (2003). Consequences of divorce in the transition from stages. Journal of Women's Studies, 3(1), 134-133. Amato, P. R, \& Rogers, S. J. (1997). Alongitudinal study of marital problems and subsequent divorce. Marriage and family, 59, 612-624. https://doi.org/10.2307/353949

Balali, T. (2009). Investigation about predict of divorce adjustment factors in divorced women in Isfahan. Master 
Dissertation, Isfahan University.

Baum, N. (2007). Separation guilt in women who initiate divorce. Clin Soc Work, J, 35, 47-55. https://doi.org/10.1007/s 10615-006-0053-5

Bloom, B., \& Hodges, W. F. (1981). The predicament of the newly separated. Community Health Journal, 17, 277-293. https://doi.org/10.1007/BF00779384

Bradbury, T. N. (Ed.). (1998). The developmental course of marital dysfunction. New York, Cambridge University Press. https://doi.org/10.1017/CBO9780511527814

Caldwell, R. A., \& Bloom, B. L., \& Hodges, W. F. (1983). Sex differences in separation and divorce: a longitudinal perspective. Issues in Mental Health Nursing, 5(1-4), 103-120. https://doi.org/10.3109/01612848309009435

Chan. H. C. S., \& Sarif, M. M. (2008). DIVORCE IN MALAYSIA. Faculty of Education, University Technology Malaysia. Skudai, Johor. 81310, 26.

Chang, J. (2003). Self-Reported Reasons for Divorce and Correlates of Psychological Well-Being Among Divorced Korean Immigrant Women. Journal of Divorce \& Remarriage, 40(1), 111-128.

Dehaghani, F. A., \& Nazari, A. M. (2010). Sociological Analysis of affecting factors in couple tendency to divorce in Isfahan City. Studies of Social Security, 14-54.

Evans, W. R. (2000) Men's experience of divorce: A qualitative study, Submitted to The Union Institute Graduate School Cincinnati, Ohio, Vol 1.

Hafarian, L., \& Aghaie, A., \& Kajbaf, M. B., \& Kamkar, M. (2009). Comparison of quality of life in Divorced women and married women and its relationship with demographic characteristics in Shiraz. Research in applied psychology. Khorasgan Azad University in Isfahan, 41, 46-86.

Honarban, M., \& Younesi, S. J. (2011). Investigation about the causes of divorce in family court of Tehran. Journal of Clinical Psychology, 3(1), 126-153.

Javadi, A. M., \& Javadi, M. (2011). The tendency to divorce and the factors affecting it in referring to family court in the west of Ivan city and in the West of Gilan. Second National Conference Researches of Social Pathologies in Iran, Faculty of Social Science of Tehran University, Iranian Sociological Association.

Kalantari, A., \& Roshan Fekr, P., \& Javaheri, J. (2011). Over three decades of research, the causes of divorce in Iran. Journal of Family and Social Council, 53(14), 130-162.

Kalantari, A., \& Roshan, F. P. (2011). Divorce, causes and consequences, The findings of the last three decades in Iran. Second National Conference Researches of Social Pathologies in Iran, Faculty of Social Science of Tehran University, Iranian Sociological Association.

Kalmijn, M. et al. (2009) Interaction between cultural and economic determinants of divorce in the Netherlands. Marriage and Family, 66(1), 75-89.

Karam, H. G., \& Nazok, T. H. (2011). Divorce factors in Mazandaran. Journal of Cultural and Social Council for Women and Family, 53(14), 88-127.

Karami, Z. H. (2005). Comparison psychological disorder divorce( anxiety and depression) and educational failure in highschool's girls and boys in Zanjan city. Master Dissertation, University of Gilan.

Mcknight, B. A. (2009). An exploratory study of the experience of individual cohabitating through the process of divorce. A psycho clinical dissertation presented to the faculty of the California school of professional psychology alliant international university Son Diego.

Mirzadeh, F., \& Ahmadi, Kh.,\& Mirzadeh, F. (2011). Effect of emotionally therapy on women divorced in their divorce adjustments. Journal of Counseling and Psychotherapy family, 1(4), 441-460.

Naeimi, M. R. (2003). Marital satisfaction and factors affecting on it in Shiraz. Thought and Behavior, 8(4).

Pourkhan, A. (2011). Comparative study- Couples divorce scales who referred to intervene center in Family in Kerman city. Second National Conference Researches of Social Pathologies in Iran, Faculty of Social Science of Tehran University, Iranian Sociological Association.

Rahimi, H. (2000). Study of divorce factors in Khorasan city. Quarterly population, 33-34(8), 100-112.

Sadrolahshrafi, M., \& Khonakdar Tarsi, M., \& Shamkhani, A., \& Yousefi, A. M. (2012). Divorce Pathology (causes) and methods of prevent them. Journal of cultural engineering, 73-74(7), 27-53.

Seif, S. (2004). Comparison investigation about outcomes of divorce in divorced men and divorced women in America 
and Iran. Journal of family research, 1(1), 82-104.

Wiseman, S. (1975). Crisis theory and the process of divorce. Social Casework, 56, 205-212.

Zargar, F., \& Neshat Doost, H. T. (2010). Investigation in incidence of divorce factors in the city of flaverjan. Journal of family research, 11(3), 737-749.

\section{Copyrights}

Copyright for this article is retained by the author(s), with first publication rights granted to the journal.

This is an open-access article distributed under the terms and conditions of the Creative Commons Attribution license which permits unrestricted use, distribution, and reproduction in any medium, provided the original work is properly cited. 